\title{
Petroleum Hydrocarbon Degraders from Wastewater Canal Supplemented with Dry Maize Cob as Organic Carbon Source
}

\author{
Olusola Abayomi Ojo-Omoniyi*, Ruth Onyekachukwu Atewe and \\ Abdulgafar Oladipupo Onitolo
}

Department of Microbiology, Faculty of Science, Lagos State University, Lagos Badagry expressway, Lagos

*Corresponding author

\section{Keywords \\ Biodegradation, Microorganisms, Organic carbon, Petroleum hydrocarbon, Wastewater \\ Article Info \\ Accepted: 04 October 2018 Available Online: 10 November 2018}

\begin{abstract}
A B S T R A C T
Petroleum is a complex mixture composed primarily of aliphatics, alicyclics and aromatic hydrocarbons. This study was to evaluate the potentials of native bacterial population of wastewater environment with the ability for bioremediation of petroleum hydrocarbon polluted natural environment. A fresh water ecosystem west of Lagos state university, Ojo campus that has the history of being fed with both domestic wastewater and spent diesel oil served as source of bacterial samples. Serial dilution technique and total heterotrophic bacterial count for the wastewater was evaluated. The Bonny light crude oil was exposed to the wastewater canal through sterile oil-impregnated filter discs (Type HA $0.45 \mu \mathrm{m}$ diameter) supplemented with dried maize cob housed in perforated plastic balls for 30 days. The physicochemical properties of the freshwater habitat were determined prior to the introduction of oil-impregnated filter discs. Thereafter, residual petroleum hydrocarbons were subjected to Gas chromatography to determine the degree of mineralization of the Bonny light crude. The gas chromatographic profile of the residual crude oil gave the convincing evidence of mineralization of petroleum hydrocarbons by native bacterial population. The petroleum hydrocarbon utilizers were; Bacillus brevis, Pseudomonas sp., Bacillus pumilus, Micrococcus luteus and Corynebacterium sp. The use of native bacterial consortium with petroleum hydrocarbon utilizing capabilities as well as being subjected to biostimulation techniques could prove to be a more environmentfriendly approach to bioremediation of oil-polluted environment as well as enhance the processes of sustainable development rather than the use of exotic bacterial species. There were some fungal species isolated and characterized which includes; Aspergillus sp., Penicillium sp., and Fusarium sp.
\end{abstract}

\section{Introduction}

Crude oil constitutes a major source of pollution in our environment (FAQ, 2011). Petroleum is at present Nigeria's and indeed the world's most important derived energy source (Moffatand Linden, 2005). The release of hydrocarbons into the environment whether accidentally or due to human activities is the main cause of water and soil pollution (Holliger et al., 1997). Microbial degradation is the major and ultimate natural mechanism 
through which clean-up process for petroleum hydrocarbon pollutants in the environment can be achieved (Lal and Khanna, 1996). Oleophilic microbes are used in biodegradation to remove hydrocarbon pollutants from the environment (Macaulay and Rees, 2014).

Available data show that oil and gas companies operating in Nigeria burn over $\$ 3.5$ to \$5billion yearly from the over 257 flow stations in the Niger Delta. Specifically the country flared about 17.15 percent of the 95.471 metric tonnes of gas produced in June, 2015 alone, according to data from Nigerian National Petroleum Corporation (NNPC) (Anonymous, 2015).

In routine operations of crude oil production, refining and distribution unavoidable spillages occur. The demand for liquid petroleum has been on the increase, hence the need for reliable and efficient oil spill clean-up techniques (Okoh, 2003). Mechanical and chemical methods generally used to remove hydrocarbons from contaminated sites have limited effectiveness and can be expensive.

Compared to microbial products, very few nutrient additives have been developed and marketed specifically as commercial bioremediation agents for oil spill clean-up. It is probably because common fertilizers are inexpensive, readily available, and have been shown to be effective if used properly. However, due to the limitations of common fertilizers (that is, being rapidly washed out due to tide and wave action), several organic nutrient products, such as oleophilic nutrient products, have recently been evaluated and marketed as bioremediation agents (Ladousse and Tramier, 1991). Nutrients are very important ingredients for successful biodegradation of hydrocarbon pollutants especially nitrogen, phosphorus, and in some cases iron (Cooney, 1984). Some of these nutrients could become limiting factor thus affecting the biodegradation processes. Bioremediation is the promising technology for the treatment of these contaminated sites since it is cost-effective and will lead to complete mineralization. Bioremediation functions basically on biodegradation, which may results to complete mineralization of organic contaminants into carbon dioxide, water, inorganic compounds, and cell protein or transformation of complex organic contaminants to other simpler organic compounds by biological agents like microorganisms (Das and Chandran, 2011).

Bioremediation is considered one of the most sustainable clean-up techniques but the potential has not been fully exploited in the field due to the fact that it is considered to be too slow to meet the immediate demands of the environment (Macaulay and Rees, 2014).

The parameters typically measured in laboratory tests of bioremediation efficacy include enumeration of microbial populations (Kastner et al., 1994; Peressutti et al., 2003), determination or fate of hydrocarbon degradation (disappearance of individual hydrocarbons and/or total hydrocarbons (Okoro, 2008).

However, the most direct measure of bioremediation efficacy is the monitoring of hydrocarbon disappearance rates (Song and Bartha, 1990). Generally, type and identity of fresh or biodegraded oils and petroleum products can be readily revealed by their GCFID traces especially where the biodegradation of spilled oil or petroleum product is heavy and background hydrocarbon levels are low in an impacted environment. In addition to measuring TPH (Total Petroleum Hydrocarbons) in samples, GC-FID chromatograms provide a distribution pattern of petroleum hydrocarbons (such as carbon range and profile of UCM (unresolved 
complex mixture), fingerprints of the major oil components (such as individual resolved nalkanes and major isoprenoids), and information on the biodegradation extent of the spilled oil. Comparing biodegradation indicators (such as $\mathrm{nC}_{17} /$ pristine, $\mathrm{nC}_{18} /$ phytane) for the spilled oil to the source oil can also be used to monitor the effect of microbial degradation on the loss of hydrocarbons at the spill site (Wang and Fingas, 2003; Jones et al., 2008).

The objectives of the current study are to evaluate a tropical wastewater canal for indigenous petroleum-hydrocarbon degrader as well as its possible integration for any bioaugmentation strategy during bioremediation process.

\section{Materials and Methods}

\section{History of sampling site}

Wastewater sample were collected from wastewater canal at the west of Lagos State University (LASU), Ojo campus. The canal has the history of being fed with domestic wastewater from LASU staff quarters and from occasional discharge of diesel oil arising from a nearby generating house.

\section{Determination of physicochemical parameters of wastewater samples}

Water samples were collected in sterile reagent bottles. Holding the bottle in a horizontal direction, which is then plunged into the water in a downward direction to a depth of $0-30 \mathrm{~cm}$ along the course of the wastewater canal west of LASU Ojo campus that is, collecting this sample, the mouth was directed against the direction of flow. Water samples for microbiological analysis were collected in a sterile screw cap bottles and stored in the refrigerator prior to laboratory analysis.

\section{Source of crude oil samples}

Bonny light Nigerian crude oil was obtained from WalterSmith Petroman Oil Limited, Lagos.

\section{Media preparation}

The media used for the isolation and enumeration of microorganisms were prepared according to the standard specifications of the manufacturer. All media preparation was done following aseptic procedures. The media were sterilized in an autoclave at $15 \mathrm{Ib}$ for 15 minutes at $121^{\circ} \mathrm{C}$.

\section{Sterilization}

Glassware such as pipettes were sterilized at temperature of $160^{\circ} \mathrm{C}$ for 1 hour. Inoculation loop and needle were sterilized in a Bunsen burner until red-hot. Filter paper were wrapped in an aluminum foil and placed under ultraviolet light for 42 hours.

\section{Oil exposure to the environment}

Microcosm experiment for the 'in-situ' determination of oil degradation rates were carried out (Gilbert and Higgins, 1978; Amund and Igiri, 1990). Maize cobs (Zea mays) were dried in the hot - air oven for 72 hours at $70^{\circ} \mathrm{C}$. Thereafter, the dried maize cob was ground and $0.5 \mathrm{~g}$ of this was placed on sterile filter paper discs (Type HA, $0.45 \mu \mathrm{m}$ ) cob, then $2 \mathrm{ml}$ of Bonnylight crude was evenly absorbed by the ground maize cob and the filter disc. Thereafter, it was inserted into perforated plastic balls through a slit to form an equatorial diaphragm. The balls were resealed and then placed in a perforated plastic container with a flat stone for it to be submerged as well as get the container attached to a pole with a line. This was kept in the canal for 30 days with daily monitoring. The Control were then set up in the laboratory 
by immersing the plastic balls that is housing the sterile oil filter into a sterile wastewater in order to determine the effect of biological phenomena on oil leaching. The balls were in four replicates and the filter discs were withdrawn aseptically from the canal at a 10day intervals within the 30 - day period.

Each of the filters were later placed in $10 \mathrm{ml}$ of sterile wastewater in a screw cap bottles. These bottles were shaken at 200-oscillation /minute with a shaker for three hours in order to free the microorganisms from the filter paper.

\section{Enumeration of microorganisms}

Total numbers of heterotrophic bacteria in the wastewater samples were obtained by introducing aliquot $(0.1 \mathrm{ml})$ sample of appropriate dilution on nutrient agar plates or standard plate count and this is done aseptically. With the aid of a sterile hockey stick, the inoculum was spread uniformly on the agar surface, which is incubated for 18-24 hours at $28 \pm 2{ }^{\circ} \mathrm{C}$ (Okerentugba and Ezeronye, 2003; Thamer et al., 2013).

\section{Total hydrocarbon utilizing microorganisms}

The population of hydrocarbon utilizing bacteria in the samples was determined by inoculating $0.1 \mathrm{ml}$ aliquots of appropriate dilution on Minimal Salt Agar (MSA). Crude oil used as carbon sources were introduced by vapour phase transfer.

It is done by placing filter discs impregnated with the oil into the lids of petridishes (Raymond et al., 1976).

Petroleum-hydrocarbon degraders were isolated and identified by the Bergey's Manual of Determinative Bacteriology (Buchanan and Gibbons, 1974).

\section{Micromorphological and biochemical characterization}

The shape, size, pigmentation, elevation and marginal characteristics of bacteria species were examined on nutrient agar plates after appropriate incubation period and they were also microscopically examined.

\section{Colony counting}

The colony was counted with the use of a counter known as Gallenhamp colony counter (Germany). It was calculated by multiplying the average number of colonies per countable plates. This is done using the reciprocal of the dilution as colony forming unit $\backslash \mathrm{ml}$ that is, CFU \ml.

\section{Biochemical tests}

\section{Catalase}

Inoculate a nutrient agar slant and incubate at $28 \pm 2^{\circ} \mathrm{C}$. Thereafter trickle $1 \mathrm{ml}$ of $3 \%$ Hydrogen peroxide to an 18-24 hour culture that is already emulsified on a glass slide. The culture was immediately observed for the appearance of bubbles (Gerhardt et al., 1981; Alexander and Strete, 2001).

\section{Oxidase}

It was performed by adding oxidase reagent (1\% $\alpha$-naphthol in 95\% ethanol and freshly prepared $1 \%$ oxalate aqueous di-methyl-pphenylenediamine) to bacterial growth on agar plate. After the growth is combined with oxidase reagent, color changes were observed for up to 60 seconds (Gerhardt et al., 1981; Alexander and Strete, 2001).

\section{Starch hydrolysis}

With the use of a sterile transfer loop, an isolate is inoculated onto a starch medium. 
The plate was incubated at $28 \pm 2^{\circ} \mathrm{C}$ for 48 hours. After the incubation, the plate is flooded with Gram's iodine, which reacts with the starch to produce or give a purple -blue colour (Gerhardt et al., 1981; Alexander and Strete, 2001). A clear zone around bacterial growth indicates starch hydrolysis.

\section{Indole}

With the aid of a sterile transfer needle, an isolate was inoculated into a tube, the tube was incubated for $24-48$ hours at $28 \pm 2^{\circ} \mathrm{C}$. After the incubation, five drops of KOVAC'S reagent (p-dimethyl aminobenzaldehyde) was added to the agar surface. The KOVAC reagent contains amyl alcohol, hydrochloric acid and paradimethyl aminobenzaldehyde. This reagent reacts with in dole to form a red colour (Gerhardt et al., 1981; Alexander and Strete, 2001).

\section{Motility test}

With the help of sterile transfer needle, an isolate was inoculated into a tube. The needle was inserted and withdrawn in a straight line in the center or middle of the medium. The tube was incubated at $28 \pm 2^{\circ} \mathrm{C}$ for $24-48$ hours before the growth was examined along the line (Gerhardt et al., 1981; Alexander and Strete, 2001). Growth away from line of inoculation suggests the organism is motile.

\section{Gram stain}

A smear of fresh culture was made in a drop of sterile water and heat fixed. Crystal violet; which is the primary stain in the Gram staining process was applied to the fixed smear and then rinsed off under running water after 1 minute. Gram's iodine was then added to the smear and rinsed off with water after 1 minute. The smear was then decolorized with $70 \%$ ethanol and it was rinsed off immediately under a running tap. After which it was counter stained with safranin and then rinsed after 30 seconds (Gerhardt et al., 1981; Alexander and Strete, 2001).

\section{Evaluation of Residual Total Petroleum Hydrocarbon (TPH)}

Residual petroleum was quantified using gas chromatographic analysis. Residual total petroleum was extracted once as follows: The residual oil recovered from oil - impregnated filters was extracted with $10 \mathrm{ml}$ of Dichloromethane. After the solvent vented off, the residual TPH was dissolved in acetone and concentrated to $1 \mathrm{ml}$. TPH concentrations in the acetone were determined using the Hewlett Packard 5890 Series gas chromatograph OnColumn Injector type (column OV-101, thickness and width-80/100 mesh, stationary phase WHP 5\%) equipped with Flame Ionization Detector (FID). The injector and detector temperatures were maintained at $200^{\circ} \mathrm{C}$ and $260^{\circ} \mathrm{C}$ respectively. The column temperature was programmed to rise to $230^{\circ} \mathrm{C}$. The GC was programmed at an initial temperature of $70^{\circ} \mathrm{C}$, this was held for $2 \mathrm{mins}$, then ramped at $10^{\circ} \mathrm{C} / \mathrm{min}$ to $230^{\circ} \mathrm{C}$ and held for 10 mins.Nitrogen was used as the carrier gas with a pressure of $37 \mathrm{psi}$ while 1-2 $\mu 1$ of samples were respectively injected (Adebusoye et al., 2007).

\section{Results and Discussion}

The physicochemical parameters of the fresh water habitat principally determined the type and populations of petroleum hydrocarbon utilizers found in the habitat. The rate of biodegradation of petroleum hydrocarbons was also influenced by the physicochemical properties of the environment. The wastewater canal was relatively acidic and lacked the inorganic nitrates. The freshwater ecosystem has comparatively low ammonium nitrogen $\left(\mathrm{NH}_{4}-\mathrm{N}\right)$ and phosphates $\left(\mathrm{PO}_{4}\right)$, hence low population of the petroleum hydrocarbon 
degraders. The degree of turbidity observed suggested high degree of ecological reactions in the ecosystem and microbial interactions taking place (Table 1) (Abioye et al., 2012). Five bacterial strains capable of utilizing both petroleum hydrocarbons and dried maize cob as organic carbon source were isolated and characterized as well as fungal species. Although, the fungal species detected were few but they were better adapted due to the level of acidity of the habitat while a larger population of bacterial species were detected (Tables 2 and 3). Nitrogen and Phosphorus are essential nutrients for acclimation of native hydrocarbonoclastic organisms to petroleum hydrocarbons in natural environment. However, the ecosystem under investigation low $\mathrm{N}$ and $\mathrm{P}$ which stimulates the microbial consortium to utilize the available maize cob for energy.

The presence of crude oil in the natural environment inevitably distort the ecological balance of the particular ecosystem which is what gravitate to the emergence of a tropical freshwater habitat to have petroleumhydrocarbon degrader as part of its biotic component as observed in this study (FAQ, 2011). The biodegradability of crude oil components varies from different types of environment, microorganisms and crude oil. The Bonnylight crude oil was biodegraded into its intermediates with the saturated hydrocarbon fractions disappearing faster than others (Fig. 1-6). This corroborated the reports of Sugiura et al., (1996). The mean daily temperature of the wastewater which ranged from $25-27^{\circ} \mathrm{C}$, supported the acclimation of microbial consortium to petroleum hydrocarbon in a tropical wastewater. The quality of nutrient offered by this ecosystem also enhanced the populations of petroleum hydrocarbon degraders. This corroborated the findings of Cooney (1984) and Walworth et al., (2007). Despite the low $\mathrm{N}$ and $\mathrm{P}$ content of this habitat hydrocarbonoclastic organism used the dried maize cob and petroleum hydrocarbon as sources of carbon and hydrocarbon energy which is a form of biostimulation.

Table.1 Determination of physicochemical parameters of the wastewater samples

\begin{tabular}{|l|c|c|}
\hline Parameters & Sample A & Sample B \\
\hline pH & 5.88 & 5.87 \\
\hline Conductivity (uS/cm) & 159.8 & 159.4 \\
\hline Total dissolved solid (ppm) & 112.5 & 112.7 \\
\hline Turbidity (NTU) & 37 & 30.5 \\
\hline Salinity as C1-(ppm) & 80.2 & 80.1 \\
\hline Nitrate (mg/1) & 0 & 0 \\
\hline Ammonia (NH4-N) (mg/1) & 0.55 & 0.58 \\
\hline Phosphate (HPO $\left.{ }^{3}\right)$ (mg/1) & 0.21 & 0.24 \\
\hline Temperature $\left.\mathbf{(}^{\mathbf{0}} \mathbf{C}\right)$ & 26 & 27 \\
\hline $\begin{array}{l}\text { Key: } \\
\text { A- Morning } \\
\text { B - Evening }\end{array}$ & & \\
\hline
\end{tabular}


Table.2 Bacterial growth from suspended filter discs on media

\begin{tabular}{|c|c|c|c|c|c|c|}
\hline & \multicolumn{3}{|c|}{ CONTROL } & \multicolumn{3}{c|}{ SAMPLE } \\
\hline DAY & NA & PDA & MSM & NA & PDA & MSM \\
\hline & $\mathbf{1 0}^{\mathbf{1}}$ & $\mathbf{1 0}^{\mathbf{1}}$ & $\mathbf{1 0}^{\mathbf{1}}$ & $\mathbf{1 0}^{\mathbf{5}}$ & $\mathbf{1 0}^{\mathbf{4}}$ & $\mathbf{1 0}^{\mathbf{3}}$ \\
\hline $\mathbf{0}$ & 0 & 0 & 0 & 8 & 5 & 4 \\
\hline $\mathbf{1 0}$ & & & & 5 & 4 & 3 \\
\hline $\mathbf{2 0}$ & & & & 2 & 3 & 2 \\
\hline $\mathbf{3 0}$ & 1 & 3 & 2 & 2 & 3 & 1 \\
\hline
\end{tabular}

KEY:

NA: Nutrient agar

PDA: Potato dextrose agar

MSM: Minimal salt medium

Table.3 Identification of hydrocarbon - utilizing bacteria

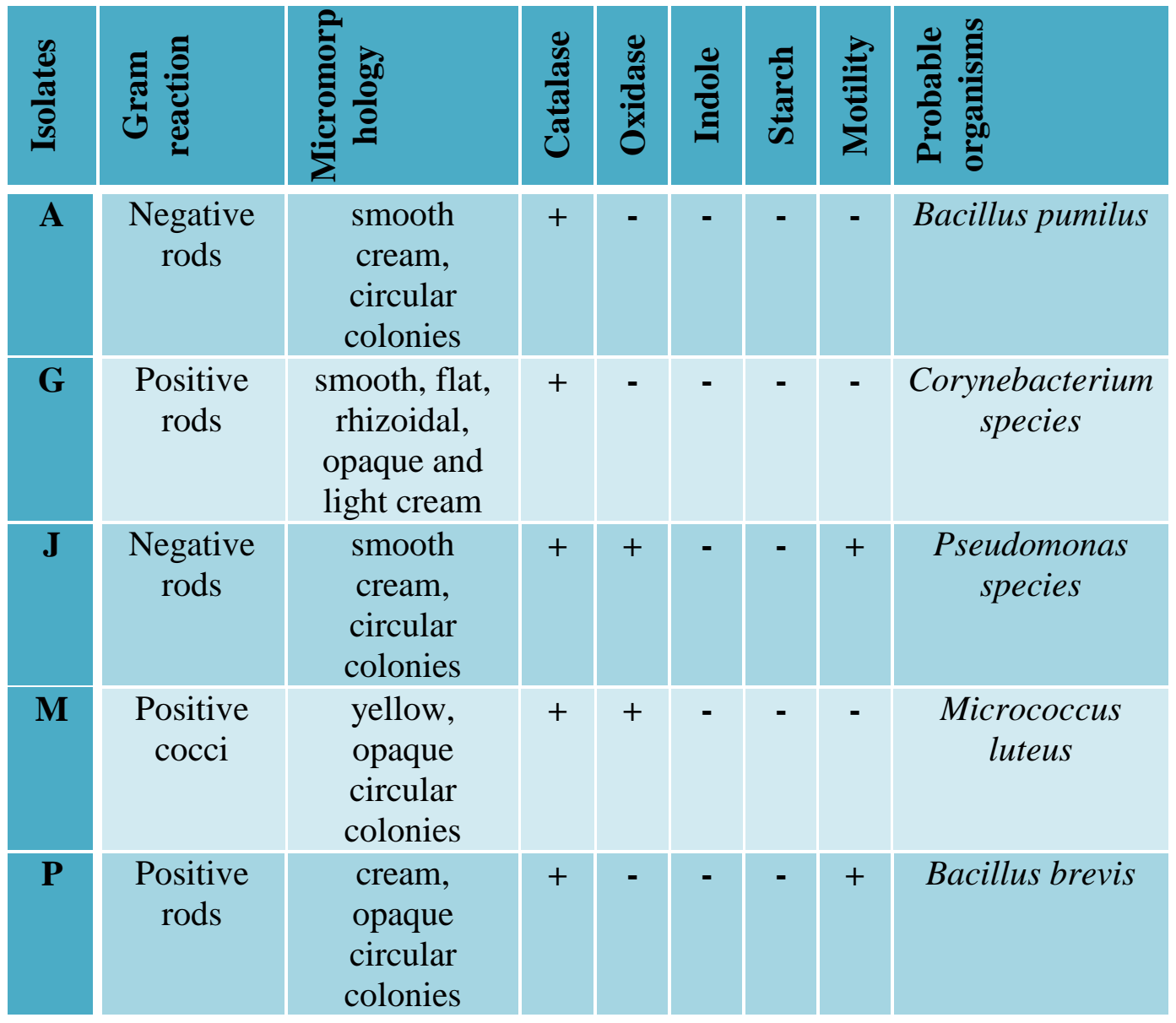

KEY

$+=$ Positive

- = Negative 
Fig.1 Time - degradation course of residual bonnylight crude oil 30-day period

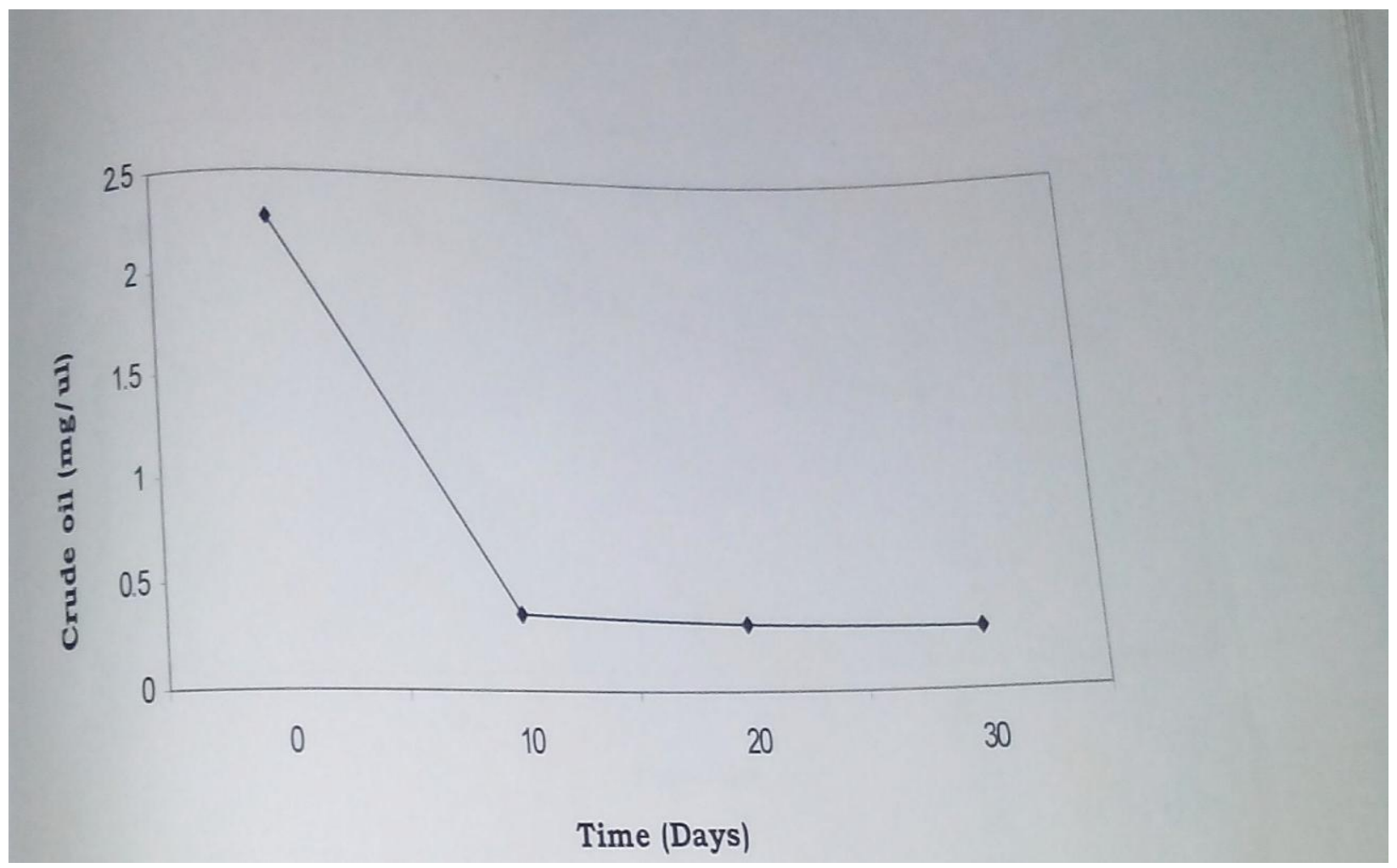

Fig.2 Time-degradation course for the control in the laboratory over 30-day period

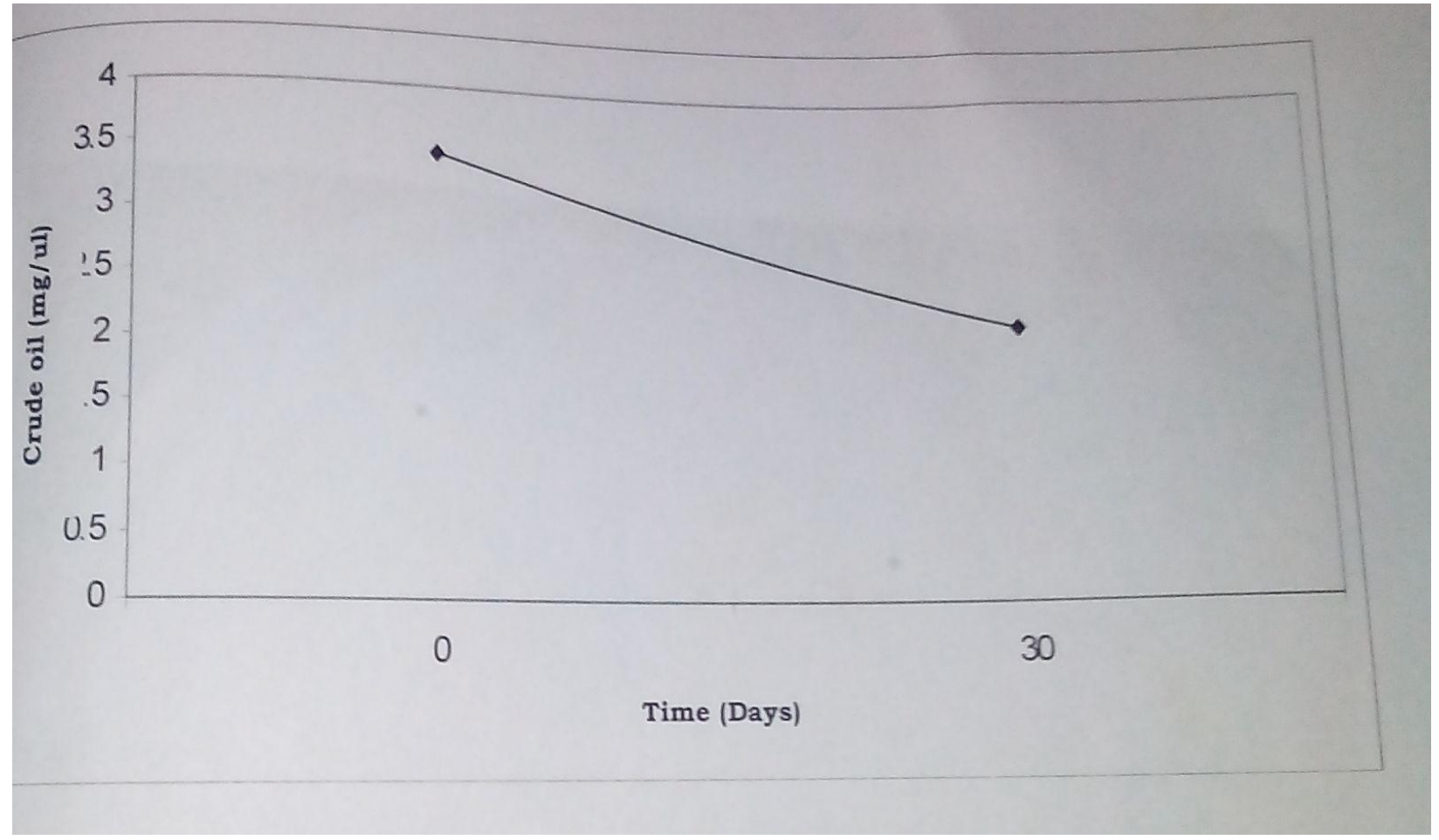


Fig.3 GC profile of bonnylight crude oil at day 0 (Microcosm)
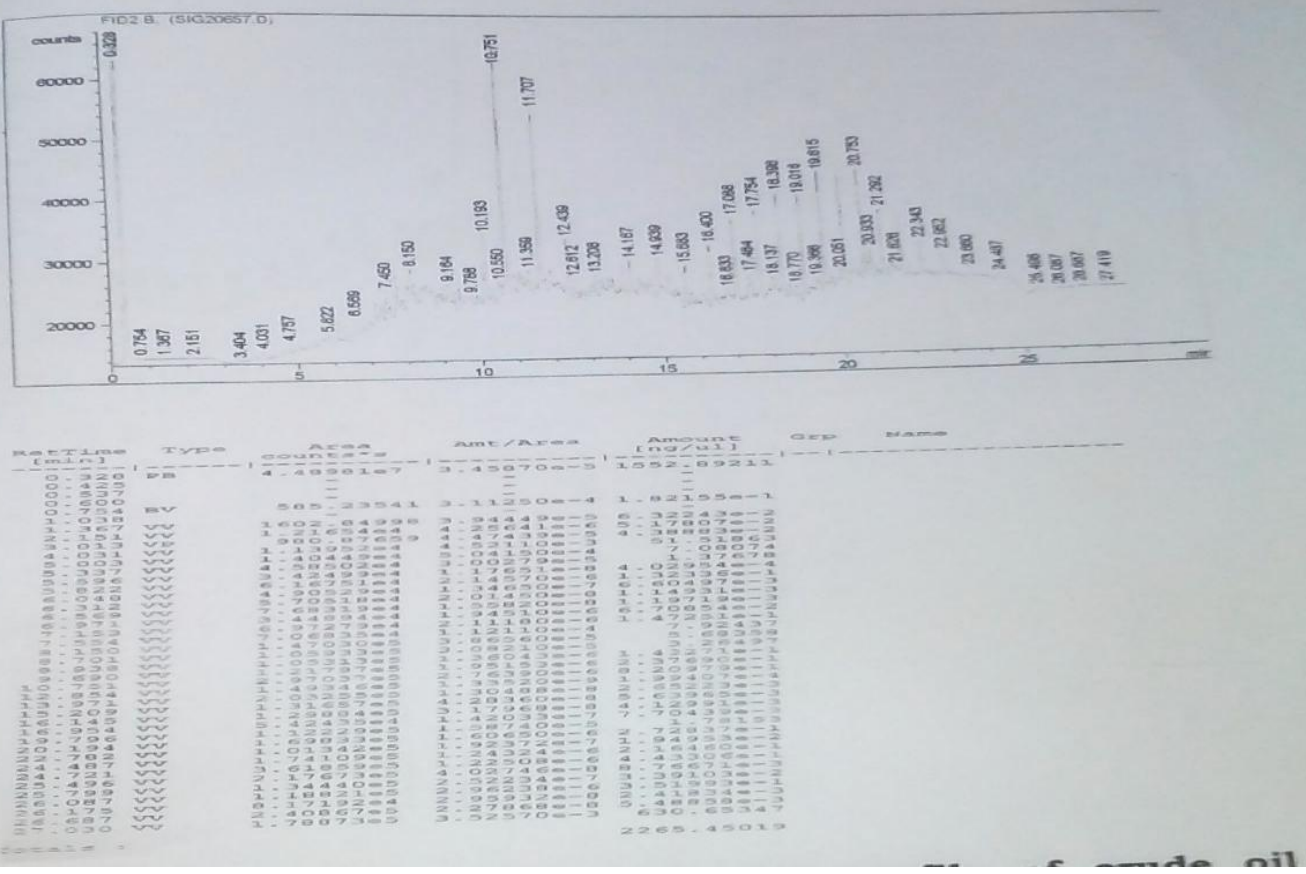

Fig.4 GC profile of bonnylight crude oil control (laboratory) day 0

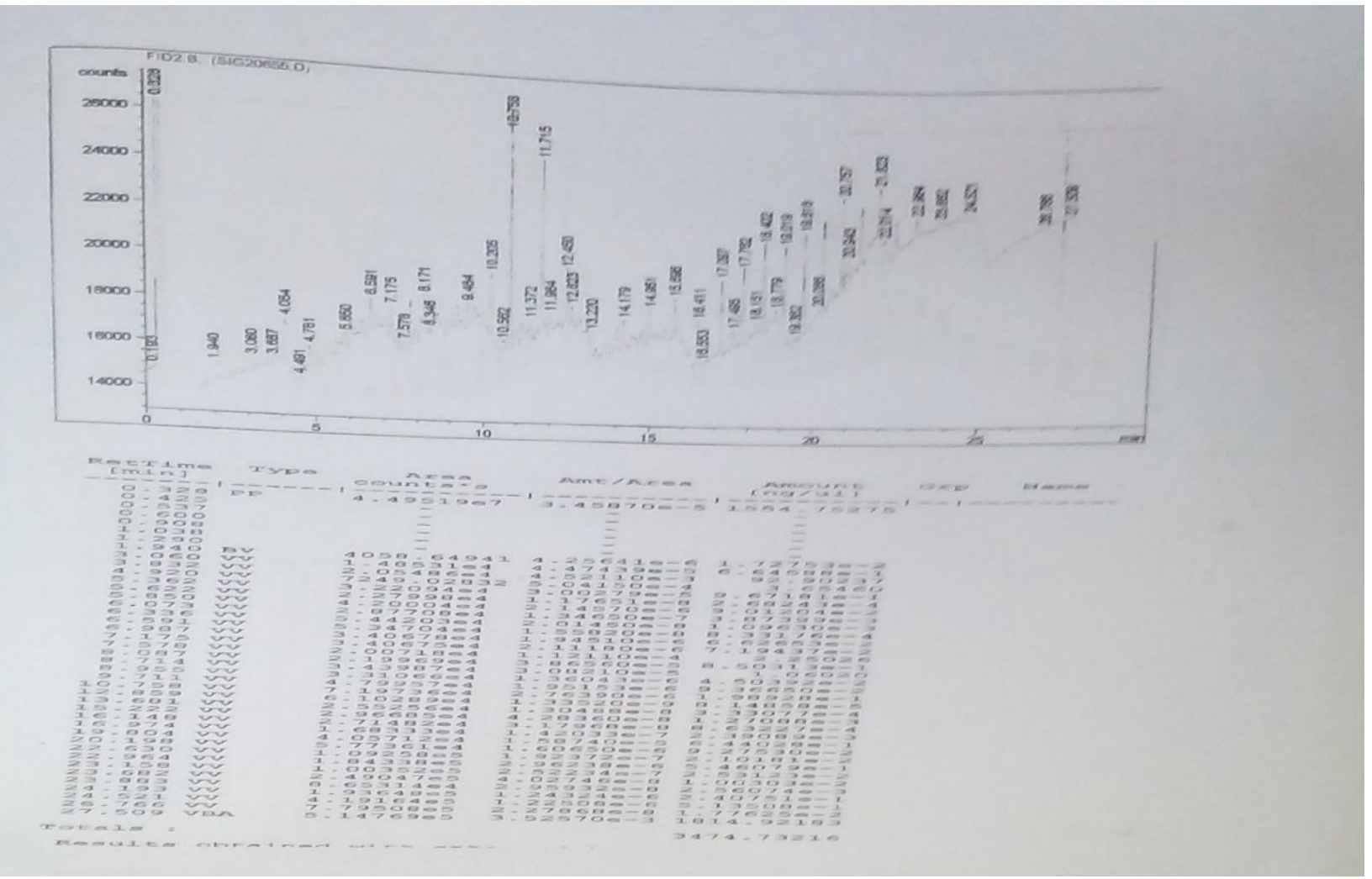


Fig.5 GC profile of residual bonnylight crude oil control day 30

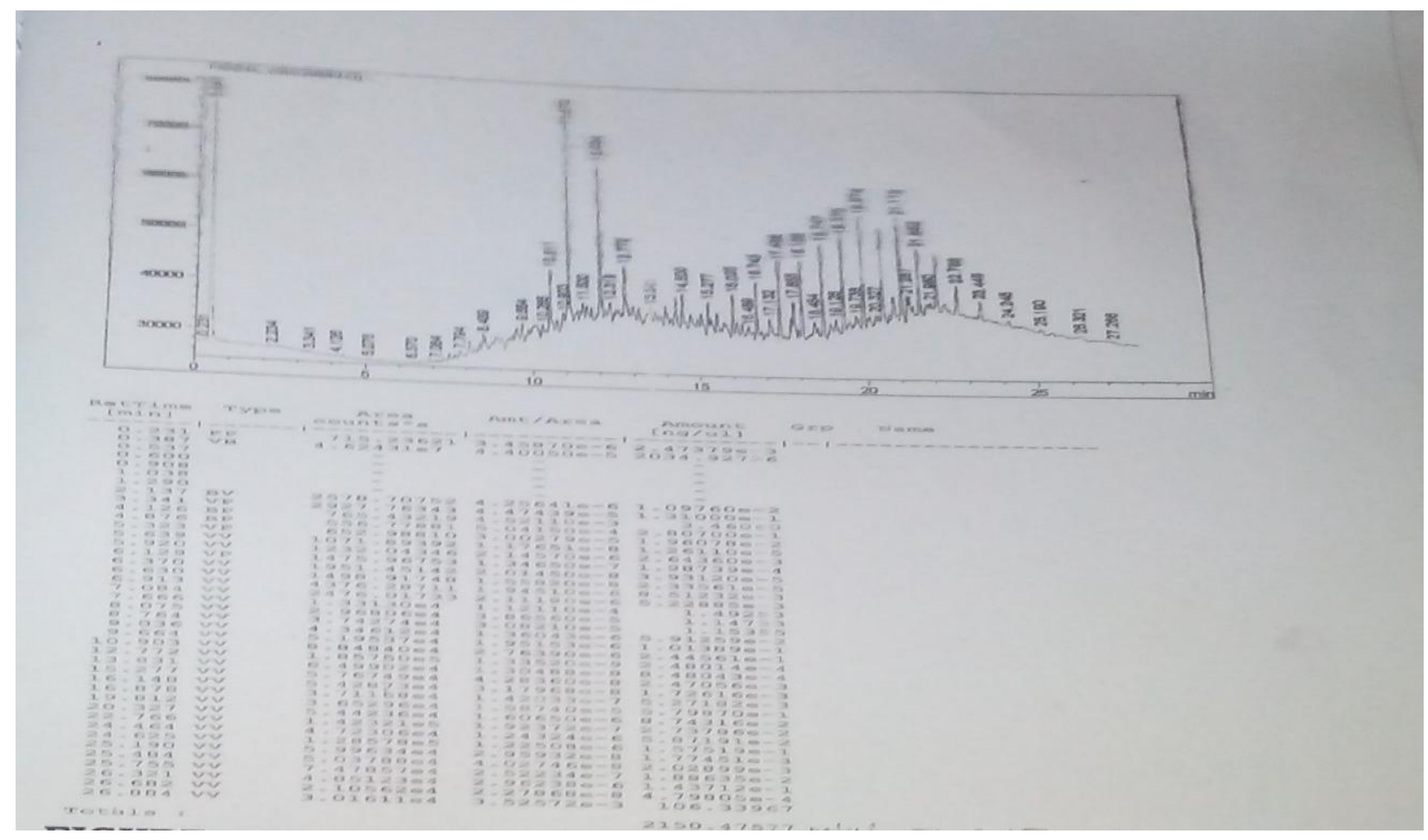

Fig.6 GC profile of residual bonnylight crude oil microcrosom day 30

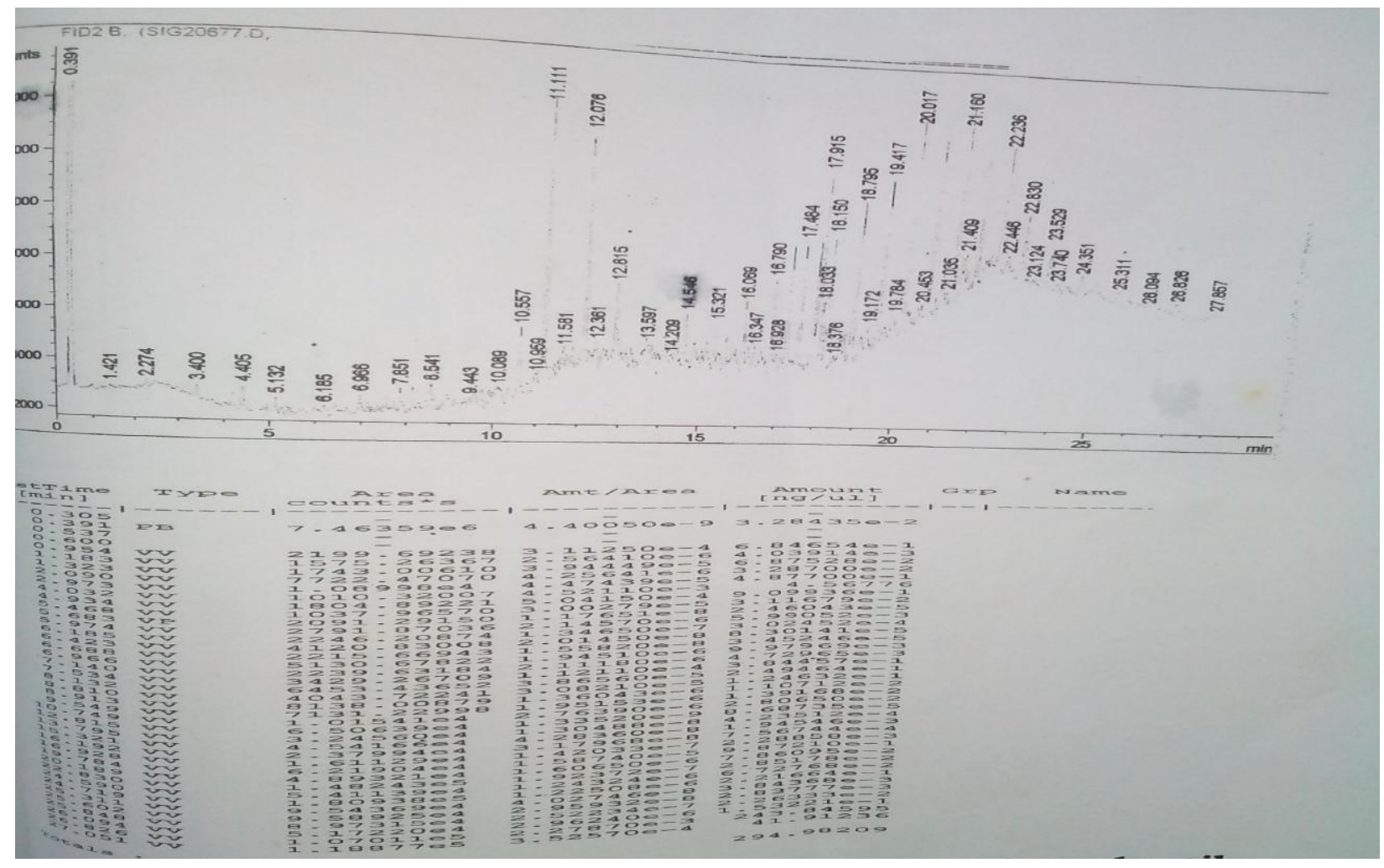


The microorganisms identified and characterized were in agreement with the findings of previous researchers, however, the Corynebacterium sp. isolated displayed novelty trait in that some of its biochemical properties were different from those previously isolated. It may form subject of future research. The speed /velocity of the wastewater suggested its highly aerated and consequently facilitated the quality of biodegradation detected over a 30-day period, since oxidation of organic materials are enhanced in presence of abundant oxygen(BOD) (Robertson et al.,1973). The findings of this research thus corroborate the assertions that microorganisms acts as a costeffective bioremediation technology particularly the integration of indigenous microbial population as reported (Kastner et al., 1994; Das and Chandran, 2011). The comparative analysis of the gas chromatographic profiles suggested significant reduction in quantity of certain petroleum hydrocarbon components as depicted by the peaks. This technology thus confirms the occurrence of biodegradation as reported by Thamer et al., (2013).

The detection of both bacterial and fungal population as mixed culture from the microcosm study revealed that no single organism has the metabolic capability to mineralize the complex petroleum hydrocarbons but a consortium. Gas chromatographic results thus provide both scientific and quantitative evidence that native microbial consortium could be a costeffective and environment-friendly means of actualizing a clean-up process for petroleum hydrocarbon- polluted natural environment.

\section{Acknowledgment}

We are grateful to Covenant University and Covenant university Center for Research and Innovation Development (CUCRID) for their timely support and sponsorship to present this paper at this conference.

\section{References}

Abioye, O. P., Agamuthu, P. and AbdulAziz, A. R. (2012). Biodegradation of used motor oil in soil using organic waste amendments. Biotechnology Research International 2012: 8p.

Adebusoye, S. A., Ilori, M. O., Amund, O. O., Teniola, O.D. and Olatope, S. O. (2007). Microbial degradation of petroleum hydrocarbons in a polluted tropical stream, World Journal of Microbiology and Biotechnology, 23(8): 1149-1159.

Alexander, S.D. and Strete, D. (2001). Microbiology: A photographic atlas for the laboratory. Benjamin cumming, an imprint of Addison Wesley Longman. Inc. Pp. 69-92.

Amund O.O., and Igiri C.U. (1990). Biodegradation of Petroleum Hydrocarbons under tropical estuarine conditions. World Journal of Microbiology\& Biotechnology 6: 225262.

Anonymous (2015). Nigeria burns off $\$ 5$ billion resources yearly from gas flaring In: Nigerian National Petroleum Corporation (NNPC) Statistical Report June, 2015. Publ. THE GUARDIAN (www.ngguardiannews.com) Nov. $6^{\text {th }}$ 2015. Pp. $25-29$.

Buchanan, R.E. and Gibbons, N.E. (1974). Bergey's Manual of Determinative Bacteriology, $8^{\text {th }}$ Edition (Eds.) R.E. Buchanan and Gibbons; N. E. The Williams and Wilkins company (publisher) Baltimore.

Cooney, J. J. (1984). The fate of petroleum pollutants in fresh water ecosystems In: Petroleum Microbiology, (Ed.)R. M. Atlas, Macmillan, New York, NY, USA, Pp. 399-434. 
Das, N. and Chandran, P. (2011). Microbial degradation of petroleum hydrocarbon Contaminants: An overview. Biotechnology Research International 2011(2011): 13p. Article ID: 941810.

FAQ (2011). Microbes \& oil spills. American Academy of Microbiology, Washington DC, 20036. www.asm.org.

Gerhardt, P., Murray, R.G E., Costilow, R.N., Nester, E. W., Wood, W. A., Krieg, N.R. and Phillips, G. B. (1981). Manual of methods for general bacteriology. American Society for Microbiology Washington, DC 20006. Pp. $409-425$.

Gilbert, P.C., Higgins, I. J. (1978). The microbial degradation of crude mineral oils at sea. Journal of General Microbiology 108:63-70.

Holliger, C., Gaspard, S., Glod, G., Heijman, C., Schumacher, W., Schwarzenbach, R.P., and Vasquez, F. (1997). Contaminated environment in the subsurface and bioremediation: Organic contaminants. FEMS Microbiology Reviews 20 (3-4): 517- 523.

Jones, D.M., Head, I.M., Gray, N. D., Adams, J.J., Rowan, A. K., Aitken, C. M., Bennett, B., Huang, H., Brown, A., Bowler. B. F. J., Oldenburg, T., Erdmann, M. and Larter, S. R. (2008) Crude-oil biodegradation via methanogenesis insubsurface petroleum reservoirs. Nature Letters 451: 176181.

Kastner, M., Breuer-Jammali, M. and Mahro, B. (1994). Enumeration and characterization of the soil microflora from hydrocarbon-contaminated soil sites able to mineralize polycyclic aromatic hydrocarbons. Applied Microbiology\& Biotechnology 41: 267273.

Ladousse, A. and Tramier, B. (1991). Results of 12 years of research in spilled oil bioremediation: Inipol EAP 22," In: Proceedings of the International Oil
Spill Conference American Petroleum Institute, Washington, DC, USA Pp. 577-581.

Lal, B. and Khanna, S. (1996). Degradation of crude oil by Acinetobacter calcoaceticus and Alcaligenes odorans. Journal of Applied Bacteriology81: 355 -362 .

Macaulay, B. M and Rees, D. (2014). Bioremediation of oil spills: A review of challenges for research advancement. Annals of Environmental Science8: 9 37.

Moffat, A. O. and Linden, P. (2005). Perception and reality. Journal of Environmental Science \& Technology 1: 283-297.

Okerentugba, P.O. and Ezenronye O.U. (2003). Petroleum degrading potentials of single and mixed microbial cultures isolated from rivers and refinery effluent in Nigeria. African Journal of Biotechnology 2(9): 288-292.

Okoh, A.I., (2003). Biodegradation of bonny light crude oil in soil microcosm by some bacterial strains isolated from crude oil flow stations saver pits in Nigeria. African Journal of Biotechnology 2: 104-108.

Okoro, C.C. (2008). Biodegradation of hydrocarbons in untreated produce water using pure fungal cultures. African Journal of Microbiology Research2: 217-223.

Peresutti, S. R., Alvarez, H.M. and Pucci, O.H. (2003). Dynamics of hydrocarbondegrading bacteriocenosis of an experimental oil pollution in Patagonian soil. International Biodeterioration \& Biodegradation 52(1): 21-30.

Robertson, B., Arhelger, S., Kinney, P. J. and Button, D. K. (1973). Hydrocarbon degradation in Alaskan waters In: Ahearn, D. G. and Meyers, S. P. (Eds.), Microbial Degradation of oil pollutants, 
Louisiana State University, Pp. 171184.

Song, H.G. and Bartha, R., (1990), Effects of jet fuel spills on the microbial community of soil. Applied and Environmental Microbiology56: 646651.

Sugiura, K., Ishihara, M., Shimauchi, T. and Harayana, S. (1996). Physicochemical properties and biodegradability of crude oil. Environmental Science \& Technology 31(1): 45-51.

Thamer, M., Al-kubaisi, A. R., Zahraw, Z., Abdullah, H. A., Hindy, I. and Khadium, A. A. (2013). Biodegradation of Kirkuk light crude oil by Bacillus thuringiensis, Northern of Iraq. Natural Science 5(7): 865- 873.

Walworth, J., Pond, A., Snape, I. Rayner, J., Ferguson, S. and P. Harvey, P. (2007). Nitrogen requirements for maximizing petroleum bioremediation in a subAntarctic soil. Cold Regions Science \& Technology, 48(2): 84-91.

Wang, Z. and Fingas, M.F. (2003). Development of oil hydrocarbon fingerprinting and identification techniques. Marine Pollution Bulletin 47(9-12): 423 - 452.

\section{How to cite this article:}

Olusola Abayomi Ojo-Omoniyi, Ruth Onyekachukwu Atewe and Abdulgafar Oladipupo Onitolo. 2018. Petroleum Hydrocarbon Degraders from Wastewater Canal Supplemented with Dry Maize Cob as Organic Carbon Source. Int.J.Curr.Microbiol.App.Sci. 7(11): 3443-3455. doi: https://doi.org/10.20546/ijcmas.2018.711.395 